\title{
I don't feel confident providing remote consultations. What do I need to know?
}

\author{
Because of the covid-19 pandemic more doctors than ever are consulting with patients remotely. \\ Doctors share their advice on remote consultations with Abi Rimmer
}

Abi Rimmer

The BMJ

\section{Reach for the familiar}

Richard Daniels, paediatric registrar, says, "As a result of the changes to our usual practice, many of us are rapidly trying to come to terms with providing healthcare remotely — an entirely different practice to our norm. Therefore, it's completely understandable to feel nervous about how we'll manage this new challenge.

"One method is to reach for the familiar-we already call patients for short reviews or to notify them of test results and then document this in the notes. Think about your practice there: what do you do to prepare, how do you conduct the consultation, and what steps do you take afterwards? Using that familiar structure helps us to think about what needs to happen.

"Make sure you have enough time, an appropriate place, and the right equipment-at the minimum a phone and access to any software needed. Test this beforehand.

"Consider which consultations are appropriate and safe for remote review, and which still need a face-to-face appointment. Inform the patient of the time to expect your call and how long it will last—and try to stick to this. Prepare for a clinic as you would normally in advance. Make sure you've been to the toilet before starting and have got something to drink.

"When starting, introduce yourself and anyone else on the call. Make sure you take and record consent and explain what will happen if you get cut off at the outset. Be clear and direct with your questions - all the normal non-verbal communication is now lost. At the end of the call, summarise the key points and check the patient's understanding. Explicitly say goodbye before ringing off and document as you normally would.

"Most importantly, this is an evolving area so be flexible and feed back what works well and what needs improvement."

\section{The fundamentals remain the same}

Sue Carr, deputy medical director at the General Medical Council and consultant nephrologist at University Hospitals of Leicester NHS Trust, says, "This pandemic has transformed the way we all work, with many doctors delivering care by remote consultations for the first time. It's been inspiring to see the profession's fast and flexible response to the situation.
"Some great resources are available to help doctors make the
most of remote consultations. A webinar from NHS England
and NHS Improvement ${ }^{1}$ and the University of Oxford's guide
for practice support the rapid roll-out of video consultations in $_{\text {primary care; while in secondary care there's guidance from }}$
NHS England and NHS Improvement ${ }^{3}$ as well as specialty
specific information produced by several royal colleges."
"We've published updated advice on the covid-19 page" of our
ethical hub to support existing guidance on remote
consultations.
"Whether you consult with patients face-to-face or remotely,
the fundamental principles remain the same: provide effective,
evidence based treatments that serve patients' needs. Listen to
your patients, share all the information they may need, and tailor
your communication to each person, in order to reach a shared
understanding.
"Before prescribing, make sure you have adequate knowledge
of your patient's health, based on up-to-date assessment. While
it's sometimes challenging to assess patients remotely, research
shows it can be safe and effective, and it's even possible to
carry out a limited physical examination by video call.
"But there will always be circumstances where patients need to
be seen face-to-face: if a condition is potentially life threatening
or if it's not clear whether a patient understands the conversation.
As this should be every doctor's first consideration, we've
published advice to help doctors decide whether the clinical
need to see a patient in person outweighs the concern about
infection risk.
"We can see the enormous pressures that doctors are under and
we know that, as always, the care and safety of patients is the
first concern. We hope our guidance gives them the confidence
they need to deliver safe and effective care."
Prepare yourself and the patient

Camille Gajria, GP and clinical teaching fellow at Imperial College London, says, "My first video consultation was a mess. Builders were drilling, the microphone failed, a colleague walked in, and lockdown was imminent. But even experienced remote consultants face challenges, so the first thing you need to know is that you're not alone. 
"Next, prepare yourself. Remote consultations have been introduced at a phenomenal speed which means there may be unintended or unforeseen problems. If you have organisational responsibility, make sure you check all the relevant regulations around things such as general data protection regulation.

"Remember that remote consulting is new for many patients too, so help them to prepare. I send patients information asking them to be ready at the agreed time, ideally in a confidential place with good wifi connection and with any vital sign readings ready. Similarly, prepare your own environment and make sure your equipment works.

"For the consultation itself, you'll use existing skills. You can do more examinations than you might think, though beware of cognitive biases-for example, a child playing in the background may not be the child being discussed. Rashes project poorly on video; securely sent photos are better.

"You don't have to use one modality exclusively. My colleagues often start consultations on the phone and move to video briefly when needed.

"There are many resources to upskill you such as indemnity organisations' webinars and royal college e-modules. Everyone is learning. Soon you'll be remote consulting like its second nature. That messy consultation? I apologised, called the

\section{Patient safety is paramount}

Sukhpreet Dubb, oral and maxillofacial surgery trainee, Addenbrooke's Hospital, Cambridge, says, "You are not alone. As an oral and maxillofacial trainee, my thought before starting my first remote consultation was, 'What if I miss a cancer? How do I examine under the tongue over the phone?'

"It's hard to believe that remote consultations can fully replace the traditional clinic appointment. Instead, they're another tool allowing clinicians to perform safely.

"Ensuring binary questions can be answered is helpful—is this patient safe? Are they well or unwell? Can I provide enough of a safety net remotely? This is akin to the 'eye ball' test when first seeing a patient walk through the door.

"What's important to realise is that although a remote consultation in many instances can't replace the benefits of a physical meeting this doesn't mean that the clinical standard for safety should fall. Indeed, the standards for communication skills, the clinical acumen to consider differentials without physical examination, and consultation documentation are pushed ever higher.

"Most important of all is patient safety. If the accumulation of history, risk factors, and clinical judgment justify it, a physical consultation should always be considered.

"Adopting digital medicine is no different to adopting a new computer system. It often feels foreign, the language seems completely different, and there are glitches or bugs. Nonetheless, it's an essential tool and one that we will continue to use long after this pandemic passes."

1 NHS England and NHS Improvement. Primary care webinar on covid-19. 27 March 2020. https://soundcloud.com/nhsengland/primary-care-webinar-on-covid-19-27-march-2020.

2 University of Oxford. Video consultations: a guide for practice. March 2020. https://bjgplife. com/wp-content/uploads/2020/03/Video-consultations-a-guide-for-practice.pdf.

3 NHS England and NHS Improvement. Specialty guides. www.england.nhs.uk/coronavirus/ secondary-care/other-resources/specialty-guides.

4 Royal College of General Practitioners. Remote consultation and triaging. https://elearning rcgp.org.uk/mod/page/view.php?id=10551-covid-19.

5 Royal College of Physicians. Effective remote consultations. www.rcplondon.ac.uk/ education-practice/courses/effective-remote-consultations.

6 Royal College of Psychiatrists. Covid-19: remote consultations. www.rcpsych.ac.uk/mentalhealth/treatments-and-wellbeing/remote-consultations-and-covid-19.

7 General Medical Council. Coronavirus: your frequently asked questions. www.gmc-uk. org/ethical-guidance/ethical-hub/covid-19-questions-and-answers.

8 General Medical Council. Remote consultations. www.gmc-uk.org/ethical-guidance/ethicalhub/remote-consultations.

9 Greenhalgh T, Shaw S, Wherton J, et al. Real-world implementation of video outpatient consultations at macro, meso, and micro levels: mixed-method study. $J$ Med Internet Res 2018;20:e150. 10.2196/jmir.9897 29625956

10 General Medical Council. Remote consultations. www.gmc-uk.org/ethical-guidance/ethicalhub/covid-19-questions-and-answers\#Remote-consultations.

Published by the BMJ Publishing Group Limited. For permission to use (where not already granted under a licence) please go to http://group.bmj.com/group/rights-licensing/ permissions 